\title{
Thermo-mechanical performance assessment of selected plates from MP-1 high power experiments
}

\author{
Hakan Ozaltun, Barry H. Rabin \\ June 2017
}

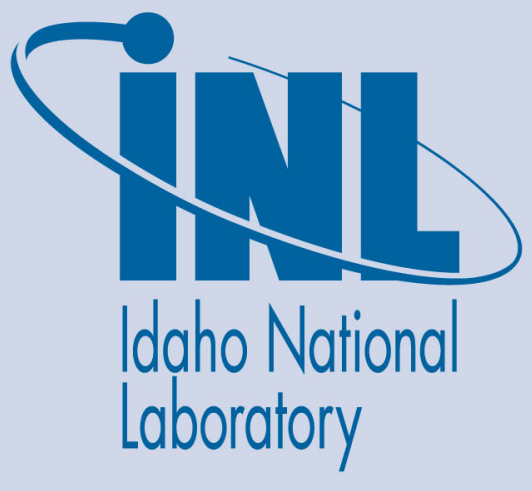

The INL is a U.S. Department of Energy National Laboratory operated by Battelle Energy Alliance 


\title{
Thermo-mechanical performance assessment of selected plates from MP-1 high power experiments
}

\author{
Hakan Ozaltun, Barry H. Rabin
}

June 2017

Idaho National Laboratory Idaho Falls, Idaho 83415

http://www.inl.gov

Prepared for the U.S. Department of Energy National Nuclear Security Administration Under DOE Idaho Operations Office Contract DEAC0705ID14517 


\section{PowerEnergy2017-03271}

\section{THERMO-MECHANICAL PERFORMANCE ASSESSMENT OF SELECTED PLATES FROM MP-1 HIGH POWER EXPERIMENTS}

\author{
Hakan Ozaltun \\ Idaho National Laboratory \\ Idaho Falls, ID, USA
}

\author{
Barry H. Rabin \\ Idaho National Laboratory \\ Idaho Falls, ID, USA
}

\begin{abstract}
Monolithic plate-type fuel is a fuel form that is being developed for the conversion of high performance research and test reactors to low-enrichment uranium fuels. These fuel-plates are comprised of a high density, low enrichment, U-Mo alloy based fuel foil encapsulated in an aluminum cladding. To benchmark this new design, number of plates has been irradiated with satisfactory performance. As a part of continuing evaluation efforts, a set of plates covering range of operational parameters is scheduled to be tested during MP-1 irradiation experiments. It is necessary to evaluate the thermo-mechanical performance of plates during irradiation. For this, selected plates with distinct operational histories; covering low power, high power and high fission density were simulated. Fully coupled threedimensional models of plates with a capability to evolve mechanical and thermal properties of constituent materials with irradiation time and burn-up were developed. The models input used projected parameters, including plate geometry, irradiation history and coolant conditions as input. The model output included temperature, displacement and stresses in the fuel, cladding and diffusion barrier. The fuel behavioral model considered inelastic behavior including volumetric swelling due to solid and gaseous products, irradiation induced creep, thermal expansion, conductivity degradation and plasticity. A visco-plastic behavioral model was used for the cladding that included thermal creep, irradiation hardening, growth due to fast neutrons and Mises plasticity. The plates were then simulated by using projected irradiation parameters. The resulting temperature, displacement and stress-strains were comparatively evaluated on the selected paths. The results were then compared with those of plates from previous RERTR experiments.
\end{abstract}

Keywords: U-Mo, monolithic fuel, mini-plate, irradiation

$\triangle$ Corresponding author: email: hakan.ozaltun@inl.gov

Tel: (208) 526-0274 Fax: (208) 526-2930

\section{INTRODUCTION}

In accordance with the Global Threat Reduction Initiative (GTRI), there are ongoing efforts to reduce and guard radiological materials at civilian sites worldwide. The main objective of Office of Material Management and Minimization (M3) is to achieve a permanent threat reduction by minimizing and eventually eliminating use of highly enriched uranium (HEU) around the world. This objective is being fulfilled by several subprograms: reactor conversion, material removal and disposition. Reactor conversion program aims to develop technologies to convert test reactors to operate with a proliferation resistant, low enriched uranium fuels. Although many test reactors can be converted with existing licensed LEU fuel, several high power reactors requires higher density fuels in a monolithic form. Within this concept, US High Performance Research Reactors (HPRR) Fuel Qualification program has been developing U-Mo alloy based monolithic fuels to support reactor conversion efforts.

The development of these fuels requires many design challenges to maintain sufficient reactor power levels, while continuing to meet safety and viability requirements. U-Mo alloy fuel is considered due to its preferential response during irradiation. Studies have shown that molybdenum extends the cubic gamma phase, which provides increased stability under irradiation. Two types of U-Mo fuel have been experimentally tested to meet reactor requirements, dispersion fuel and monolithic fuel. U-Mo dispersion fuel has shown good performance for low fission densities $(4.8 \mathrm{~g}-\mathrm{U} / \mathrm{cm} 3)$; however, some high power reactors require higher fuel densities $(>8.0 \mathrm{~g}$ $\mathrm{U} / \mathrm{cm} 3$ ) in a monolithic form in order to maintain high reactivity. U-10Mo alloy based monolithic fuel plates were selected for the conversion of several US reactors. Irradiation experiments demonstrated that U-10Mo alloy based monolithic fuels has a good swelling response and predictable in-service behavior [1]. 
Fabrication of a monolithic plate involves several steps. The initial stage of the fabrication process is the preparation of coupons made of U10Mo alloy. For this, Uranium and Molybdenum feedstock is melted in an inert atmosphere and casted into thin sheets. The sheets are machined or rolled to produce thin coupons. In order to control inter-diffusion phenomenon which occurs at the fuel-cladding interface during the irradiation process, U10Mo coupons are laminated with Zirconium diffusion barrier prior the hot rolling process. To apply Zirconium liners on each faces of the coupons, co-rolling technique is used. For this, U10Mo coupon is placed between two thin Zirconium layers (Zr-U10Mo-Zr). The layers are then positioned in a frame made of low carbon steel. Cover plates are placed to the top and bottom of the layers; and finally, the assembly is welded before the rolling process. The sheets are hot rolled at approximately $650{ }^{\circ} \mathrm{C}$. Multiple hot rolling passes is performed to minimize micro cracks. Once reduction via hot co-rolling is completed, the coupon assembly is then placed into a furnace for 45 minutes at $650{ }^{\circ} \mathrm{C}$ to reduce the residual stresses and minimize the material anisotropy. Finally, heat treated $\mathrm{Zr}-\mathrm{U} 10 \mathrm{Mo}$ co-rolled foils are removed from the rolling assembly by trimming the perimeters of coupons. The final stage of the foil preparation is to reduce the thickness of $\mathrm{Zr}$ U10Mo co-rolled foil to its targeted value via cold rolling process. Typical thickness reduction is $0.015-0.025 \mathrm{~mm}$ per pass. Final thickness of the fuel varies depending on the reactor application, ranging from $0.203 \mathrm{~mm}$ to $0.635 \mathrm{~mm}$. Finally, the co-rolled foils are encapsulated in a cladding material via Hot Isostatic Pressing (HIP), completing the fabrication process. For this, a co-rolled foil (trimmed to target dimensions prior HIP) is placed between two layers of Aluminum cladding material. These layers are subjected to a HIP procedure conducted at $560{ }^{\circ} \mathrm{C}$ and $104 \mathrm{MPa}$ for 90 minutes before being cooled to room temperature at a rate of $4.8{ }^{\circ} \mathrm{C} / \mathrm{min}$ with diminishing pressure as explained in details elsewhere [2].
A large number of plates considering range of geometries were irradiated during previous RERTR experiments. A new mini plate experiment campaign, called "MP-1" is being designed to assess the performance of the plates for various geometries under a range of irradiation conditions. The collective experiment set is being designed to test two different fuel meat thicknesses at three different irradiation conditions. The two fuel configurations are defined as "thick meat" and "thin meat". The three irradiation conditions are defined to be "LP - low power", "MP - medium power", and "HP - high power". The MP-1 fuel configurations and irradiation conditions were selected to mimic prototypic conditions for research reactors targeted for conversion to Low Enriched Uranium (LEU) fuel. In particular, HP and MP are to be irradiated in the south flux trap of the Advanced Test Reactor (ATR). HP and MP are planned to be irradiated for one and five cycles, respectively. The LP experiments will be irradiated for 8 cycles, in the B-10, B-11, and B-12 positions of ATR [3].

To assess overall performance, selected plates from MP-1 experiments were simulated. This article addresses a "thin meat" fuel irradiated at "high power" condition. The MP-1 high power experiment in the ATR SFT (southwest flux trap) is an irradiation test of fueled mini-plates similar to the previous RERTR mini-plate test campaigns. MP-1 test trains can be inserted into either of the MP-1 SFT basket positions in the SFT of the ATR. Each test train will have 2 capsules centered about the axial core mid-plane located in the B and C capsule positions. Each capsule has 2 rows of 4 columns of fuel plates for a total of 8 fuel plates per capsule. The capsules will be oriented edge-on meaning the thin edge (thickness) of the plate faces the center flux trap. The plates in the capsule will be numbered 1 through 4 on the upper row and 5 through 8 on the lower row with plates 1 and plate 5 being closest to the SFT [3]. Plate dimensions that were used in this work are in Figure 1.

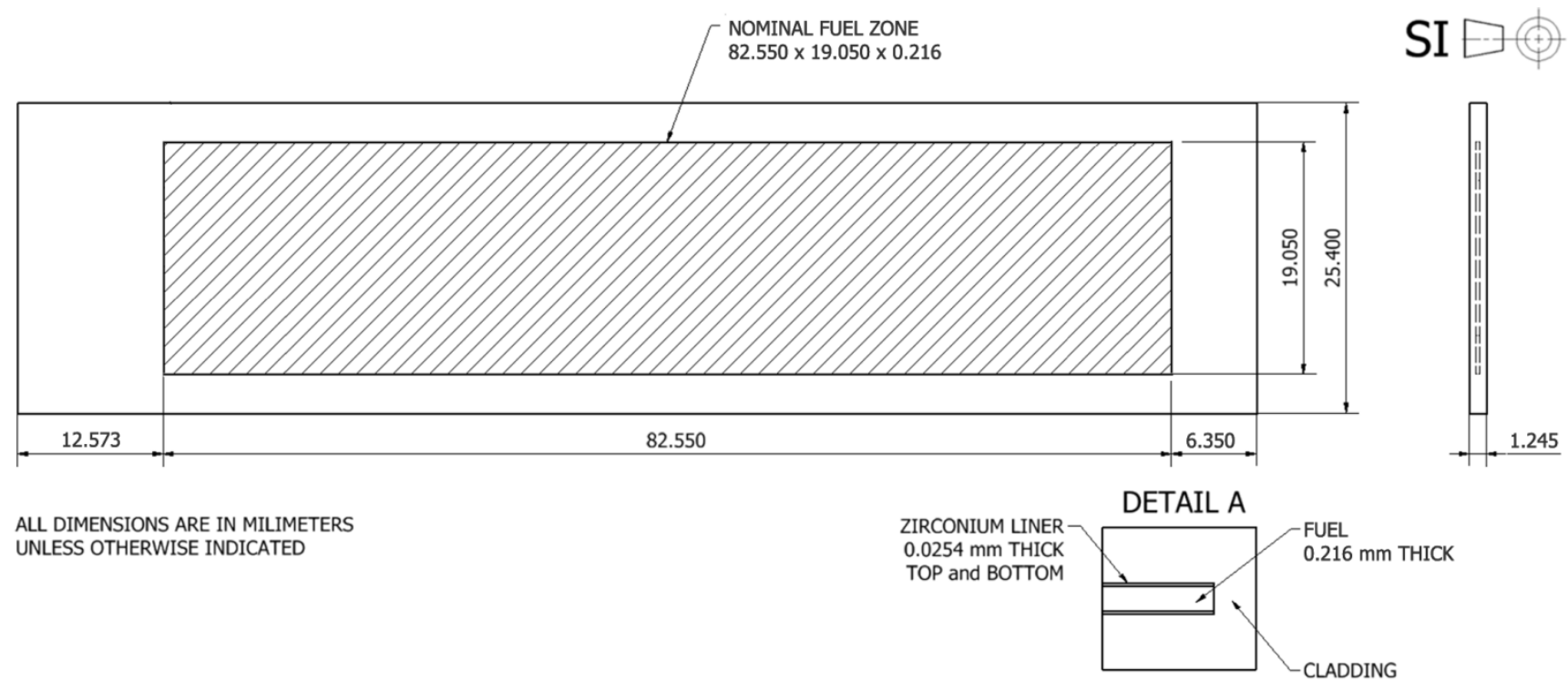

Figure 1 Plate dimensions. A high power plate (Right C5) is shown 


\section{IRRADIATION PARAMETERS}

For this work, a plate with a characteristic irradiation history from high power experiments was simulated. The plate is MP1 RC5, a "thin fuel" irradiated at high power. The plate is planned to be irradiated during a single cycle, ATR cycle 173B. Total irradiation time is 53 days (1272 hours). The plate will be oriented edge-on configuration, meaning the thin edge (thickness) of the plate faces the center flux trap.

Anticipated average fission power density for RC5 is 32776.64 $\mathrm{W} / \mathrm{cm}^{3}$, average fission density is $5.666 \mathrm{E}+21\left[\mathrm{fission} / \mathrm{cm}^{3}\right]$, and average fast neutron flux is $2.220 \mathrm{E}+18\left[\mathrm{n} / \mathrm{m}^{2}-\mathrm{sec}\right]$. Volumetric heat generation rate, fission power density, fast neutron flux and fluence, fission density local to average ratio (L2AR), and 2D distribution in fuel are shown in Figure 2 and Figure 3.

\section{BEHAVIORAL MODELS}

Fuel plates operate in an extreme environment that induces complex multi-physic interaction. This requires incorporation of complex material models to handle nonlinearities that occur in material properties. The models are generally empirical, and they are created by using correlations from the data in literature. The models consider temperature, fission density and neutron flux dependent properties. The materials are: U10Mo for the fuel zone, Zirconium for the diffusion barrier, Al6061-O for the cladding, and water at $2.5 \mathrm{MPa}$ for the coolant.

\section{Fuel (U-10Mo) Material Model}

Behavioral models include elasticity, plasticity, thermal expansion, irradiation creep, volumetric swelling, modulus
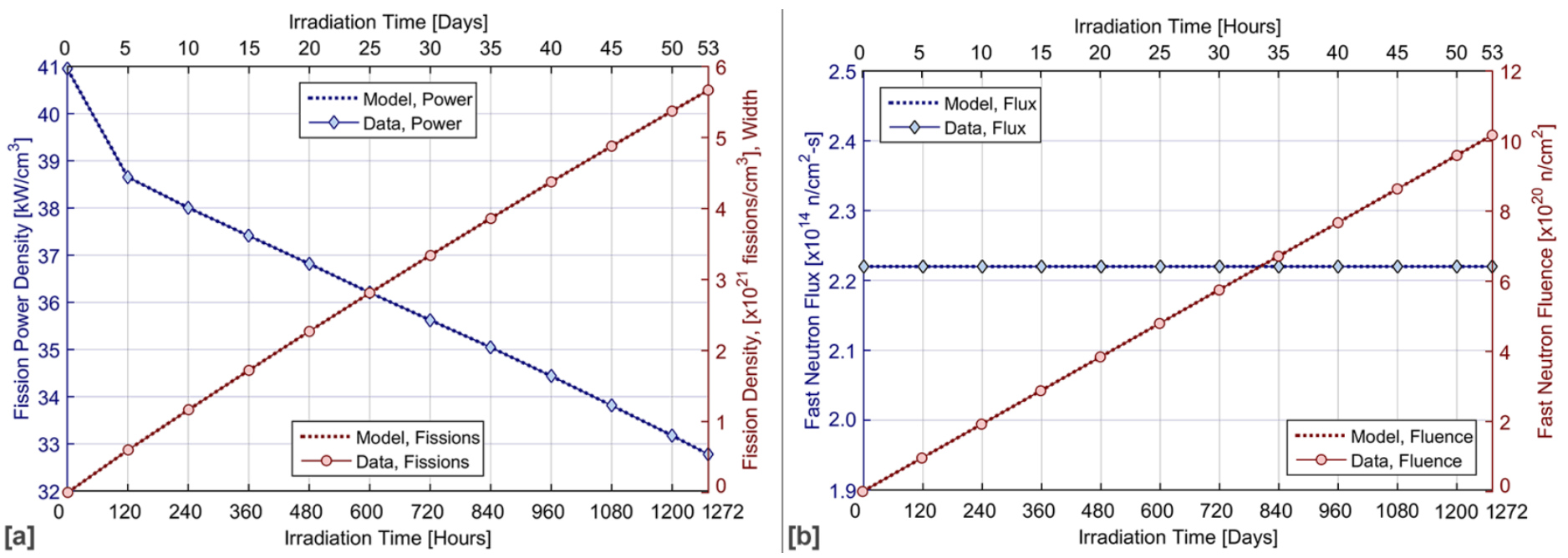

Figure 2 Irradiation Parameters (a) Power and Fission densities (c) Fast neutron flux and fluence
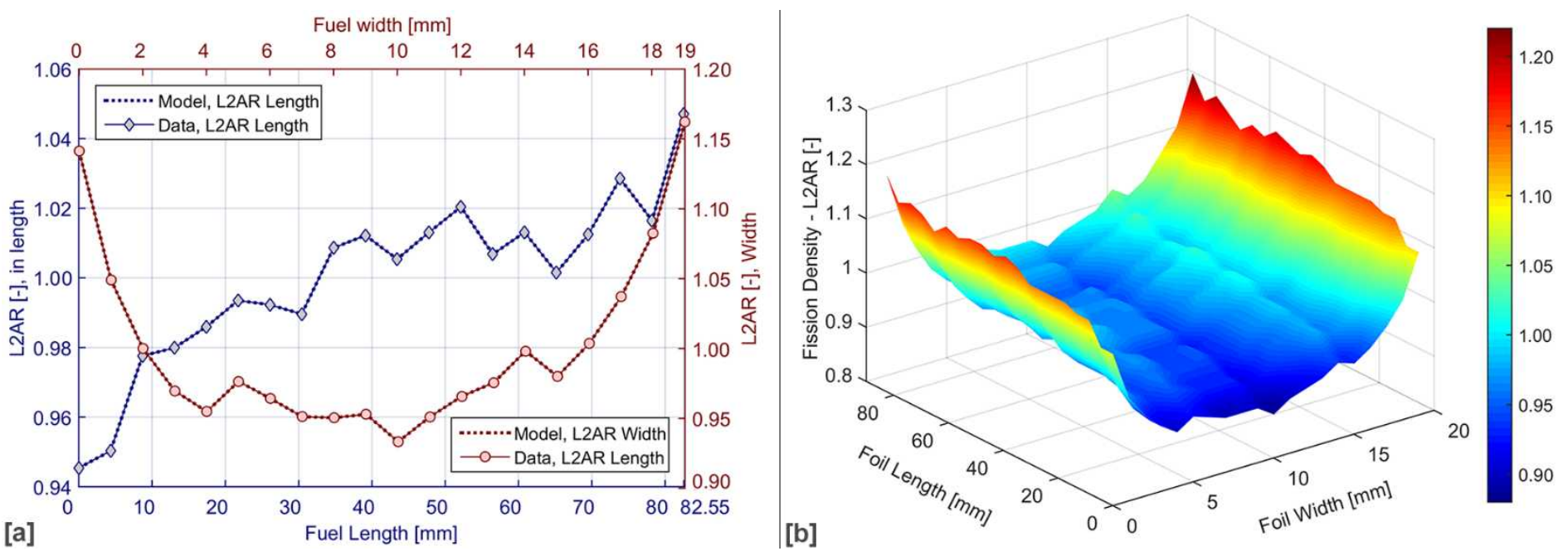

Figure 3 Fission Density, L2AR (a) Axial and transverse direction (c) 2D field in the fuel 
degradation, thermal conductivity degradation due to porosity increase. The thermal and mechanical models are based on temperature and burnup dependent data available in the literature.

Conductivity model is based on U-Mo handbook [4] as follows,

$$
\begin{aligned}
& \mathrm{k}_{U-M o}^{0}=\left(1-\sqrt{1-x_{M o}}\right) \cdot k_{M o}+ \\
& \sqrt{1-x_{M o}} \cdot\left\{\left(1-x_{M o}\right) \cdot k_{U}+x_{M o} \cdot k_{c, M o}\right\}
\end{aligned}
$$

where $\mathrm{k}_{U-M o}^{0}(\mathrm{~W} / \mathrm{m}-\mathrm{K})$ is unirradiated thermal conductivity of fuel, $x_{M o}$ is the $M o$ content in weight fraction $\left(x_{M o}=0.1\right.$ for U10Mo). In the model, $k_{M o}, k_{U}$ and $k_{c, M o}$ are expressed as;

$\mathrm{k}_{M o}(T)=150.0+4.0 \times 10^{-2} \mathrm{~T}$

where, $k_{M o}$ is the thermal conductivity of Molybdenum (W/m$\mathrm{K})$, and $\mathrm{T}$ is temperature in $(\mathrm{K}),(300 \leq \mathrm{T} \leq 800 \mathrm{~K})$.

$\mathrm{k}_{U}(T)=21.73+0.01591 \mathrm{~T}+5.907 \times 10^{-6} \mathrm{~T}^{2}$

where, $k_{U}$ is the thermal conductivity of Uranium $(\mathrm{W} / \mathrm{m}-\mathrm{K})$, and $\mathrm{T}$ is temperature in $(\mathrm{K}),(255 \leq \mathrm{T} \leq 1173 \mathrm{~K})$.

$$
\begin{aligned}
\mathrm{k}_{c, M o}= & -274.4+985.2 \cdot x_{M o}-1.941 \times 10^{3} \cdot x_{M o}{ }^{2} \\
& +3.640 \times 10^{-2} \cdot T+7.36 \cdot 10^{-5} \cdot T^{2} \\
& +5.793 \times 10^{-2} \cdot x_{M o} \cdot T
\end{aligned}
$$

where, $k_{c, M o}$ is a result of the regression analysis of the data to the equation, and $\mathrm{T}$ is temperature. The valid temperature range is $300 \leq \mathrm{T} \leq 800 \mathrm{~K}$.

Thermal conductivity of the fuel was degraded according to following relation,

$\mathrm{k}_{U-M o}=\frac{1}{4} \cdot\left[A+\left(A^{2}+8 \cdot \mathrm{k}_{U-M o}^{0} \cdot k_{g}\right)^{\frac{1}{2}}\right]$

where $\mathrm{k}_{U-M o}(\mathrm{~W} / \mathrm{m}-\mathrm{K})$ is the thermal conductivity of irradiated fuel, $\mathrm{k}_{U-M o}^{0}(\mathrm{~W} / \mathrm{m}-\mathrm{K})$ is the thermal conductivity of the fully dense material, $k_{g}(\mathrm{~W} / \mathrm{m}-\mathrm{K})$ is pore thermal conductivity. The pore thermal conductivity is expressed as;

$\mathrm{k}_{g}=0.1 \cdot\left(8.247 \times 10^{-5} \mathrm{~T}^{0.8363}\right)+0.9 \cdot(4.351$
$\left.\times 10^{-5} \mathrm{~T}^{0.8616}\right)$

$\mathrm{A}=(2-3 P) \cdot \mathrm{k}_{U-M o}^{0}+(3 P-1) \cdot \mathrm{k}_{g}$

$P=\frac{1}{100}\left\{\frac{\left(\frac{\Delta V}{V_{0}}\right)_{g}}{1+\left(\frac{\Delta V}{V_{0}}\right)_{g}}\right\}$

where, $\mathrm{P}$ is porosity factor in fraction, $\left(\frac{\Delta V}{V_{0}}\right)_{g}$ is volumetric swelling in fraction due to gaseous products.
The model for gaseous swelling is based on Kim [5]

$$
\begin{array}{r}
\left(\frac{\Delta V}{V_{0}}\right)_{g}=1.0 \cdot f_{d} \quad \text { for } f_{d} \leq 3 \times 10^{27} \text { fissions } / \mathrm{m}^{3} \\
\left(\frac{\Delta V}{V_{0}}\right)_{g}=3.0+2.3 \cdot\left(f_{d}-3\right)+0.33 \cdot\left(f_{d}-3\right)^{2} \\
\text { for } f_{d}>3 \times 10^{27} \text { fissions } / \mathrm{m}^{3}
\end{array}
$$

where $\left(\Delta \mathrm{V} / \mathrm{V}_{0}\right)_{\mathrm{g}}$ is volumetric swelling $(\%)$ due to gaseous products, $f_{d}$ is the local fission density in $\times 10^{27}$ (fissions $/ \mathrm{m}^{3}$ ).

The model for the coefficient of thermal expansion is based on experimental data by Beghi [6],

$\alpha=8.4696+0.01018 \cdot T-3.0426 \times 10^{-7} \cdot T^{2}$

where $\alpha$ is the thermal expansion $(1 / \mathrm{K})$, and $\mathrm{T}$ is temperature $\left({ }^{\circ} \mathrm{K}\right)$. Valid temperature range is $294 \leq \mathrm{T} \leq 1073{ }^{\circ} \mathrm{K}$.

The density model is based on the data by Klein [7],

$\rho=17391+0.884 \cdot T$

where $\rho$ is density in $\left(\mathrm{kg} / \mathrm{m}^{3}\right), T$ is temperature in $(\mathrm{K})$. Valid temperature range for the model is $294 \leq \mathrm{T} \leq 973^{\circ} \mathrm{K}$.

Specific heat model is based on the data by Beghi [6],

$C_{p}=114.46+7.4145 \times 10^{-2} \cdot T$

where $C_{p}$ is specific heat $(\mathrm{J} / \mathrm{kg}-\mathrm{K}), \mathrm{T}$ is temperature $(\mathrm{K})$. Valid temperature range is $273 \leq \mathrm{T} \leq 1273{ }^{\circ} \mathrm{K}$.

The model for the modulus is based on the data by Beghi [6]

$$
\begin{aligned}
E(T)=110.84- & 72.926 \times 10^{-3} \cdot T \\
- & 1.8718 \times 10^{-5} \cdot T^{2}
\end{aligned}
$$

where $E$ is Young's modulus $(\mathrm{GPa}), T$ is temperature $(\mathrm{K})$. Equation is valid for $294 \leq \mathrm{T} \leq 873^{\circ} \mathrm{K}$.

Degradation model of modulus at room temperature is based on the experimental data given in [8].

$E(f d)=94.3-5.4 \times f d$

where $E$ is Young's modulus (GPa), $f_{d}$ is fission density in $\times 10^{21}$ (fis $/ \mathrm{cm}^{3}$ ). The equation is for room temperature and valid up to fission densities of $7 \times 10^{21}\left(\mathrm{fis} / \mathrm{cm}^{3}\right)$. There is no available degradation model for higher temperatures. To implement a modulus degradation model at higher temperatures, unirradiated data at elevated temperatures (Eqn.14) was extrapolated by using the ratios at the room temperatures by (Eqn.15). 
Poisson's ratio was adapted from [9] and it is constant 0.324 .

Plasticity model is based on the data by Klein [7].

$$
\begin{gathered}
\sigma_{y}=-1.2727 \times 10^{-6} \cdot T^{3}+2.430 \times 10^{-3} \cdot T^{2} \\
-2.4285 \cdot T+1478.6
\end{gathered}
$$

where $\sigma_{y}$ is yield strength in (MPa), and ), $T$ is temperature in $\left({ }^{\circ} \mathrm{K}\right)$. Valid temperature range is $300 \leq \mathrm{T} \leq 866^{\circ} \mathrm{K}$.

The irradiation creep model of the fuel is based on Kim [10],

$\dot{\epsilon}=A \cdot \sigma \cdot \dot{f}$

where, $\dot{\epsilon}$ is creep strain rate $(1 / \mathrm{sec}), A$ is irradiation induced creep coefficient $\left(500 \times 10^{-25} \mathrm{~cm}^{3} / \mathrm{MPa}\right), \sigma$ is equivalent stress $(\mathrm{MPa})$, and $\dot{f}$ fission density rate (fissions $/ \mathrm{cm}^{3}-\mathrm{sec}$ ).

The model for the fuel meat swelling due to fission products is based on the relation given by Kim [10] as,

$$
\begin{array}{r}
\left(\frac{\Delta V}{V_{0}}\right)_{f}=5.0 \cdot f_{d} \quad \text { for } f_{d} \leq 3 \times 10^{27} \text { fissions } / \mathrm{m}^{3} \\
\left(\frac{\Delta V}{V_{0}}\right)_{f}=15.0+6.3 \cdot\left(f_{d}-3\right)+0.33 \cdot\left(f_{d}-3\right)^{2} \\
\text { for } f_{d}>3 \times 10^{27} \text { fissions } / \mathrm{m}^{3}
\end{array}
$$

where $\left(\frac{\Delta V}{V_{0}}\right)_{f}$ is total volumetric swelling in $(\%)$ and $f_{d}$ is the local fission density in $\times 10^{27}$ (fissions $/ \mathrm{m}^{3}$ ). The relation is valid for the fission densities below $8.2 \times 10^{27}$ fissions $/ \mathrm{m}^{3}$.

\section{Cladding (Al6061) Material Model}

Cladding material of U-Mo monolithic fuel plates is aluminum. As-received aluminum is in T6 temper. Tension tests on HIP processed aluminum indicated that high HIP process at $560{ }^{\circ} \mathrm{C}$ effectively anneals the cladding material, resulting in properties similar to those in Al6061-O [11, 12], on which the cladding properties in modeling activities are based. Although the cladding material is annealed by HIP process, cladding hardening occurs as a results of fast neutrons. Examination of available data indicated that the cladding properties become somewhat similar to those in Al6061-T4 at around $1.5 \times 10^{25}$ $\mathrm{n} / \mathrm{m}^{2}$. Because of a high non-linearity in material properties occurs during irradiation; physical, thermal and mechanical properties of aluminum were implemented as functions of irradiation exposure and temperature to accurately represent the behavior. A visco-plastic material constitution included elasticity, plasticity, thermal expansion, neutron hardening, creep, axial growth. The thermal and mechanical models are based on temperature and fluence dependent data, which include density [13], specific heat capacity [13], conductivity [13], coefficient of thermal expansion [13], Young's modulus,
[14], yield and ultimate strength [14], irradiation hardening [15], growth [16] due to fast neutrons, thermal creep and stress relaxation [14]. Additional details and the tabulated data for the cladding material can be found elsewhere [17].

\section{Diffusion Barrier (Zr) Material Model}

Earlier RERTR experiments revealed that an interaction layer develops at the interface of cladding and fuel, which consequently affects the bond strength. To minimize the potential fuel-cladding interaction, $0.025 \mathrm{~mm}$ thick zirconium layer between the U-Mo foil and Al cladding is employed as a diffusion barrier. Zirconium is bonded to fuel via co-rolling technique. There are alternative application methods such arc melting and plasma spraying. Hot co-rolling has been preferred, as it has been consistently produced a good bond quality. Two types of pure zirconium are typically available: sponge zirconium and iodide-crystal bar zirconium. The difference between them is small. The sponge $\mathrm{Zr}$ is $>99.6 \%$ in purity, while the iodide crystal bar is $>99.9 \%$ pure. The iodide-crystal bar is softer, with a lower level of oxygen content (usually less than 100ppm). Because of the higher fabrication cost, the sponge zirconium is used frequently and is considered as pure. There are several factor can affect material properties, including oxygen content, grain size, precipitates and cold work ratio. Previous studies indicated that effects of $\mathrm{Zr}$ property variation on overall performance are insignificant [18].

The diffusion barrier is ASM Grade 702 commercially pure Zirconium, on which the diffusion barrier properties are based for this work. Behavioral models included elasticity, plasticity, hardening, thermal expansion and thermal creep. The thermal and mechanical models are based on available temperature dependent data, which included: density [19], specific heat capacity [19], conductivity [19], coefficient of thermal expansion [19], Young's modulus [20], yield and ultimate stress [19] and thermal creep [19]. It is reported that pure zirconium does not swell at neutron fluence up to $1 \times 10^{26} \mathrm{n} / \mathrm{m}^{2}$ at $300{ }^{\circ} \mathrm{C}$ and ion doses up to $80 \mathrm{dpa}$ in the temperature range of 300-600 ${ }^{\circ} \mathrm{C}$ [21]. Consequently, irradiation swelling was assumed to be insignificant. Additional details on $\mathrm{Zr}$ properties and tabulated data are presented elsewhere [17].

\section{Coolant Channel Model}

Models for the thermo-physical properties of the water were developed via the data reported by NIST [22]. Mathematical relations were created for the coolant at $2.5 \mathrm{MPa}$, at which the nominal operating pressure of ATR. Valid temperature range for the models is $1-100^{\circ} \mathrm{C}$. In the models below, $\mathrm{T}$ is in ${ }^{\circ} \mathrm{C}$.

Density $\left(\mathrm{kg} / \mathrm{m}^{3}\right)$ was defined according to

$\rho=1.460 \times 10^{-5} \cdot T^{3}-5.664 \times 10^{-3} \cdot T^{2}$
$+3.318 \times 10^{-3} \cdot T+1001$ 
The model for the specific heat $(\mathrm{J} / \mathrm{kg}-\mathrm{K})$ is

$$
\begin{aligned}
\rho= & 2.462 \times 10^{-6} \cdot T^{4}-6.120 \times 10^{-4} \cdot T^{3} \\
& +6.169 \times 10^{-2} \cdot T^{2}-2.459 \times T+4206
\end{aligned}
$$

Thermal diffusivity model $\left(\mathrm{m}^{2} / \mathrm{sec}\right)$ is

$$
\begin{gathered}
\alpha=1.334 \times 10^{-7}+5.562 \times 10^{-10} \cdot T-2.068 \\
\times 10^{-12} \cdot T^{2}
\end{gathered}
$$

The model for thermal conductivity $(\mathrm{W} / \mathrm{m}-\mathrm{K})$ is

$k=0.561+2.147 \times 10^{-3} \cdot T-9.565 \times 10^{-6} \cdot T^{2}$

Kinematic viscosity $\left(\mathrm{m}^{2} / \mathrm{sec}\right)$ is

$$
\begin{aligned}
\rho & =3.009 \times 10^{-14} \cdot T^{4}-8.433 \times 10^{-12} \cdot T^{3} \\
& +9.291 \times 10^{-10} \cdot T^{2}-5.321 \times 10^{-8} \cdot T \\
& +1.758 \times 10^{-6}
\end{aligned}
$$

Dynamic viscosity (Pa-s) is

$$
\begin{aligned}
\rho= & 2.986 \times 10^{-11} \cdot T^{4}-8.382 \times 10^{-9} \cdot T^{3} \\
& +9.259 \times 10^{-7} \cdot T^{2}-5.332 \times 10^{-5} \cdot T \\
& +1.760 \times 10^{-3}
\end{aligned}
$$

The model for Prandtl Number is

$$
\begin{array}{r}
\rho=2.632 \times 10^{-7} \cdot T^{4}-7.336 \times 10^{-5} \cdot T^{3} \\
\quad+7.970 \times 10^{-3} \cdot T^{2}-0.4396 \cdot T+13.13
\end{array}
$$

The Reynolds number was calculated according to

$$
R e=\frac{\rho \cdot v \cdot D_{H}}{\mu}
$$

where, $v$ is velocity and $D_{H}$ is hydraulic diameter $\left(D_{H}=\right.$ $4 \cdot A / P, A$ is the cross sectional area, $P$ is the wetted perimeter). Coolant velocities are, $13.4 \mathrm{~m} / \mathrm{sec}$ for thin channels (outer) and $14.9 \mathrm{~m} / \mathrm{sec}$ for thick (inner) channels [23, 24]. For the high power plate (Right C-5 position), the channel widths are $1.905 \mathrm{~mm}$ for the outer channel (Channel 1 and 5) and $2.540 \mathrm{~mm}$ for the inner channels (channels 2, 3, 4). The channel length is $22.555 \mathrm{~mm}$.

Nusselt number was calculated by using Petukhov-Gnielinski correlation [25] for a fully developed turbulent flow ( $\mathrm{Re}>2300)$

$$
\begin{aligned}
& N u=\frac{\left(\frac{f}{8}\right) \cdot(R e-1000) \cdot \operatorname{Pr}}{1+12.7 \cdot\left(\frac{f}{8}\right)^{1 / 2} \cdot\left(\operatorname{Pr}^{2} / 3-1\right)} \\
& f=\left(\frac{1}{0.790 \cdot \ln (R e)-1.64}\right)^{2}
\end{aligned}
$$

where, $\operatorname{Pr}$ is the Prandtl number $(0.5 \leq \operatorname{Pr} \leq 2000)$, Re is the Reynolds number $\left(3000<\operatorname{Re}<5 \times 10^{6}\right)$ and $f$ is the friction factor from the first Petukhov equation. Finally, the heat transfer coefficient was calculated as,

$h=\frac{k}{D_{H}} \cdot N u$

where, $h$ is heat transfer coefficient $\left(\mathrm{W} / \mathrm{m}^{2}-\mathrm{K}\right), k$ is thermal conductivity $(\mathrm{W} / \mathrm{m}-\mathrm{K}), D_{H}$ is hydraulic diameter $(\mathrm{m}), N u$ is the Nusselt Number. Heat transfer coefficient is shown in Figure 4.

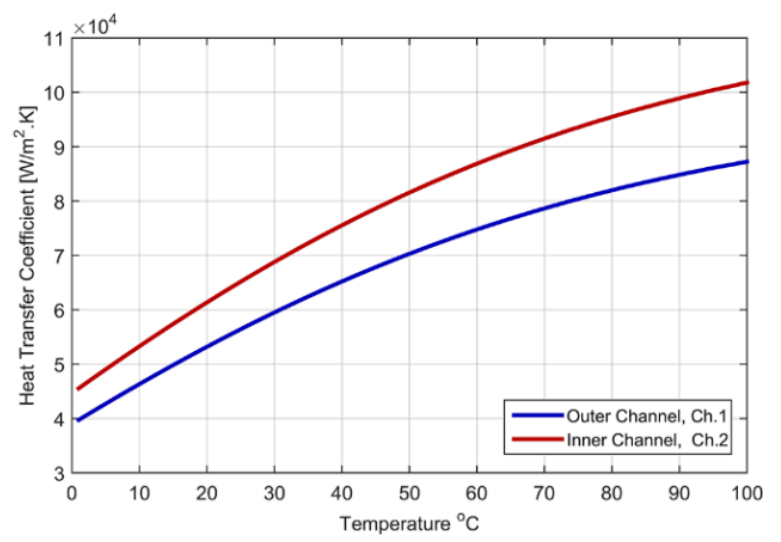

Figure 4 Heat transfer coefficient for inner and outer channels

\section{FINITE ELEMENT MODEL}

High power plates will be irradiated in a single cycle (ATR Cycle 173B). So, a representative plate (MP1, Right C5) with characteristic irradiation history was simulated for 1272 hours. In irradiation models, C3D8RT element of ABAQUS, an 8node thermally coupled brick, tri-linear displacement and temperature with reduced integration and hourglass control, was used. Equally spaced 6 layers were used to represent the thickness of the fuel. Nodal divisions along the length and width directions were 170 and 40, respectively. A total number element of the fuel was 40800 hexahedral. Zirconium diffusion barrier was represented by equally spaced 3 layers. Nodal divisions were 170 and 40, in length and width direction, respectively. Total number elements that were used to discretize diffusion barrier was 40800 hexahedral. Finally, the cladding was represented by equally spaced 18 layers through its thickness. The nodal divisions are 207 and 54, in its length and width directions, respectively. Total number of elements in cladding was 119604.

Irradiation history (Figure 2 and Figure 3) was implemented via user defined subroutines. The utility subroutine, USDFLD was used to define the local fission density within the fuel foil with respect to the spatial coordinates and the irradiation time. Fast neutron flux and fluence was also implemented in this routine. This routine was called at each material point to calculate the irradiation hardening of the cladding material. 
Constitutive relations for the Creep-Swelling-Viscoelastic behaviors of the materials were defined in the user subroutine CREEP. In this routine, (1) irradiation creep and volumetric swelling of the fuel, (2) thermal creep, irradiation creep and swelling of the cladding, (3) thermal creep of diffusion barrier were implemented.

The volumetric heat generation of the fuel foil was defined as a body heat flux in the model. This thermal load was implemented by using the local fission densities which was calculated in USDFLD routine. Porosity calculation and thermal conductivity degradation were performed in this routine also. First, the local fission densities were used to calculate the gaseous swelling. Once the gaseous swelling is calculated, the porosity was determined. And finally, the thermal conductivity was degraded according to the degradation model.

The heat transfer between the coolant and the plate surface was simulated by creating a surface interaction, which defines a film condition at the plate surfaces. Surface film condition was created by using the reported coolant temperatures [24] and calculated heat transfer coefficients.

\section{RESULTS AND DISCUSSIONS}

Both thermal and mechanical performances were evaluated. The primary purpose of thermal analysis was to predict fuel temperatures while showing that the fuel will perform without
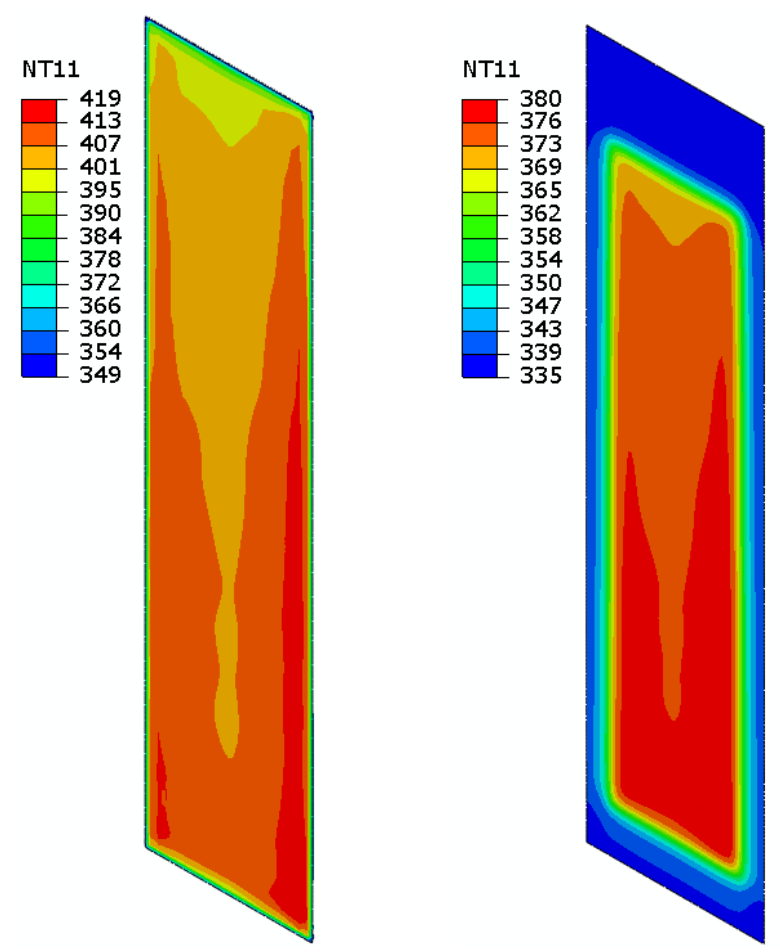

Figure 5 Temperatures $\left[{ }^{\circ} \mathrm{K}\right]$, contours are showing EOL temperatures at (a) Fuel centerline (b) Cladding surface fuel blistering or oxide spallation. The fuel blistering criteria is to show that the fuel temperature should not exceed $360{ }^{\circ} \mathrm{C}$ during a condition 2 flow coast down event. The oxide spallation threshold is $119 \Delta^{\circ} \mathrm{C}$ across the oxide layer [24].

Calculated temperatures are shown in Figure 5. Thermal and mechanical calculations are fully coupled to include non-linear geometry effects, such as thickness increase due to swelling and creep. The temperatures are shown for the end of life, just before reactor shutdown (Day 53, at 32776.64 [W/cm3]). From the contour plots, the peak temperatures are $419 \mathrm{~K}\left(146{ }^{\circ} \mathrm{C}\right)$ at the fuel centerline, and $380 \mathrm{~K}\left(107^{\circ} \mathrm{C}\right)$ at the cladding surface. These temperatures are well below blister thresholds. Temperature difference at oxide layer surfaces is also below the spallation threshold. Based on this information, a thermal issue during a normal operation is unlikely.

Purpose of mechanical analysis was to verify that mechanical integrity of the plates is preserved. Several output variables are need to be evaluated. These include, but not limited to, stresses, strains, deformations, porosity etc. The stresses and strains are needed to evaluate possible failure modes such as fuel fracture or delamination. Porosity interconnection is also checked for a possible onset of breakaway swelling. Total deformations are evaluated to check whether or not a channel closure occurs.

Figure 6 shows calculated displacement and porosity contours. Deformations were evaluated to check if a channel closure could occur. In Figure 6a, the peak displacement was calculated
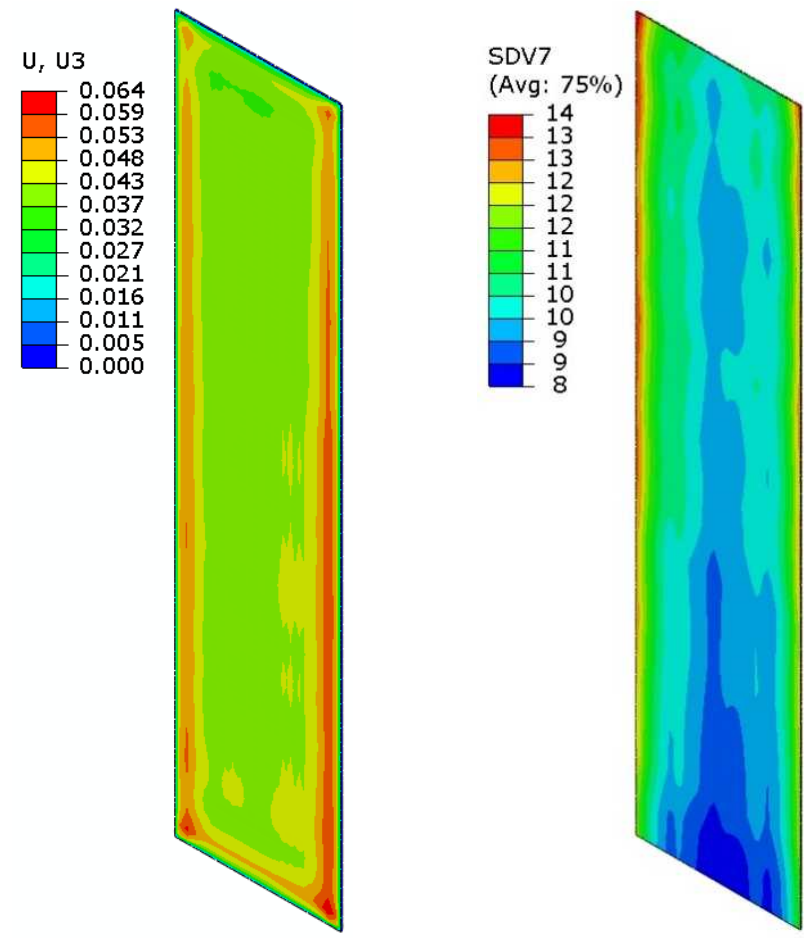

Figure 6 Fuel at shutdown (a) Thickness increase [mm], from mid-plane (b) Porosity [\%] due to gaseous swelling 
to be $0.128 \mathrm{~mm}(0.064 \mathrm{~mm}$ from mid-plane). The peaks are around the perimeter of the fuel (bulged regions, seen in red). This indicates a peak swelling strain of $60 \%$. Initial channel thicknesses are $1.905 \mathrm{~mm}$ for the outer channels (Channel 1 and 5) and $2.540 \mathrm{~mm}$ for the inner channels (Channels 2, 3, 4) in MP1 high power experiments. Although, the results indicate that roughly $7 \%$ channel thickness reduction would occur, these peak deformations are well below the channel thicknesses. Consequently, no channel blockage is expected under nominal operational conditions.

Gaseous swelling is also evaluated, as large swelling has implications on fuel integrity. It was shown that the gaseous swelling has a critical breakaway value. When gaseous swelling approaches to a critical breakaway value (33\% gaseous swelling or $25 \%$ porosity), the bubbles touch neighboring bubbles in a randomly arranged configuration, assisting interconnection of the pores [26, 27]. Based on this information, the results are evaluated to check if there are regions of possible porosity interconnection. In Figure 6b, calculated porosity contour is shown. Peak porosity was calculated to be $14 \%$, and peak gaseous swelling was $16 \%$. These magnitudes are well below the porosity interconnection thresholds. Consequently, no failure is expected due to a porosity interconnection.

There are claims that shutdown-induced stresses may contribute pillowing-type failures at shutdown. One hypothesis claims that sufficiently large tensile stresses accompanied with enough material degradation such as presence of porosity may facilitate
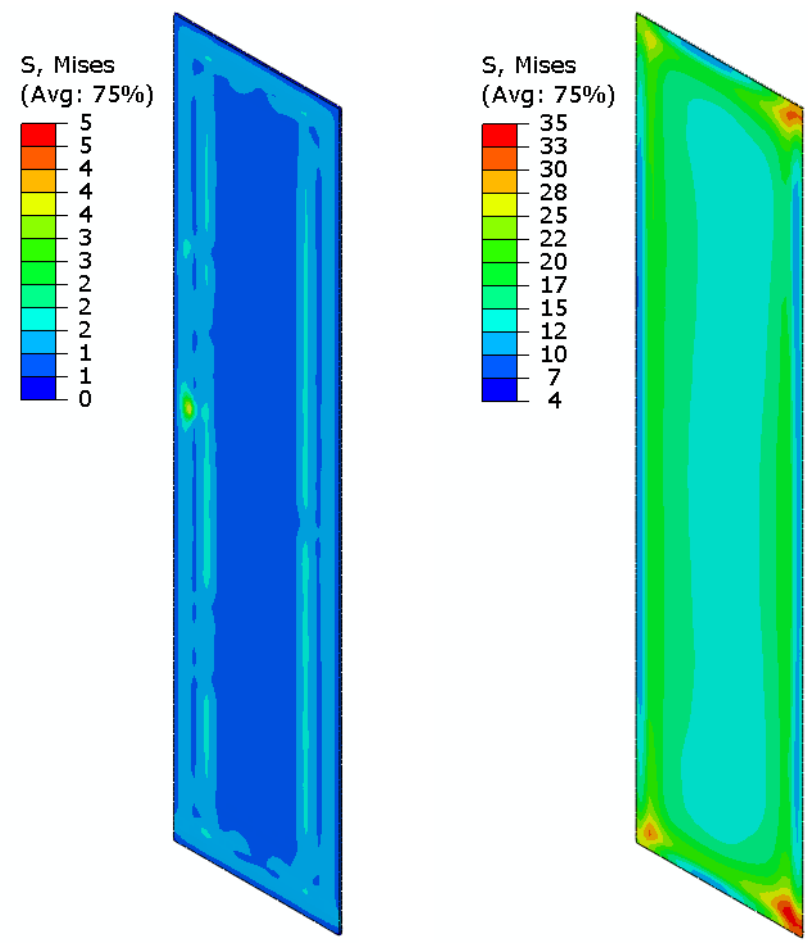

Figure 7 Equivalent stresses [MPa] in the fuel. Contours are showing (a) fuel, end of life (b) fuel, end of shutdown failures at shutdown. To check whether or not mechanically driven failures are possible, stresses-strains during operation and shutdown stages were evaluated, and the magnitudes were compared with strength of the materials

In Figure 7 and Figure 8, calculated stresses in fuel, diffusion barrier and cladding materials are shown. Fabrication simulations showed that the peak residual stress due to HIP cooling is approximately $300 \mathrm{MPa}$ in the fuel material. These stresses becomes somewhat unimportant, as any postfabrication stresses in the fuel material would be relieved relatively fast in reactor. Examination of irradiation results indicated that the fuel stresses would be relieved from fabrication stresses to less than $10 \mathrm{MPa}$ within 1 hour of irradiation. After 6 hours of irradiation, the fuel stresses become negligible and the material would be essentially stress-free during the operation. The stresses in the foil however would develop at reactor shutdown.

As shown in Figure 7, equivalent stresses in the fuel are negligible during operation (Figure 7a), but it increases to 35 $\mathrm{MPa}$ at reactor shutdown (Figure 7b). Peak fuel stresses in MP1 high power plates are considerably lower compared to those in non-failed plates of RERTR12 experiments.

Cladding stresses at shutdown is shown in Figure 8a. Unlike fuel material, the stresses in the cladding will increase during irradiation. Peak stresses due to HIP was calculated to be roughly $70 \mathrm{MPa}$ in the cladding. These stresses increase to 129 $\mathrm{MPa}$ at EOL. This increase is due to irradiation hardening by

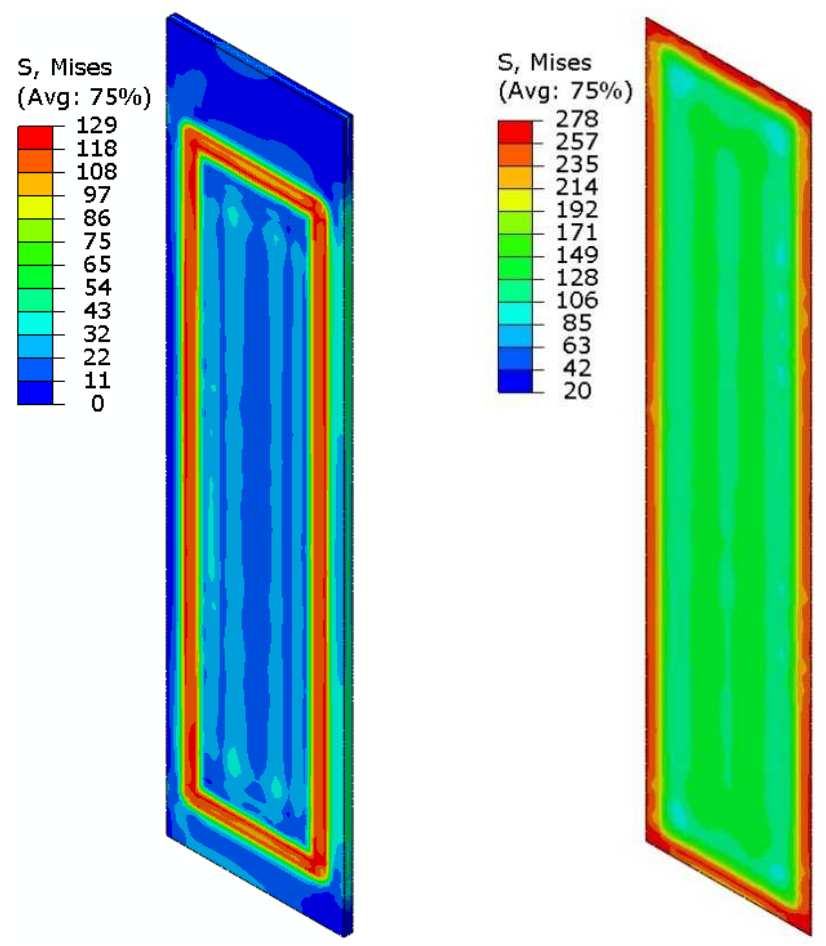

Figure 8 Equivalent stresses [MPa] at shutdown. Contours are showing stresses in (a) Cladding (b) Diffusion barrier 
fast neutrons. Additional stresses in the cladding are generated as a result of fuel's volumetric swelling.

Equivalent stresses in the diffusion barrier are shown in Figure $8 \mathrm{~b}$. The results indicate that the peaks are around the perimeter, reaching approximately $280 \mathrm{MPa}$. This magnitude is well below the ultimate strength of the diffusion barrier.

Total swelling and creep strains are also checked for a satisfactory mechanical performance. Localized large swelling strains essentially cause large creep strains, which consequently causes bulging around the perimeter of the fuel. Figure 9 shows swelling and irradiation creep strains. The peak swelling is $42 \%$ at the fuel edges. The creep strain is highest around the perimeter of the fuel, where cladding pressures are highest. The peak creep strain magnitude is $62 \%$. Minimum irradiation creep is $11 \%$, and occurs away from edges.
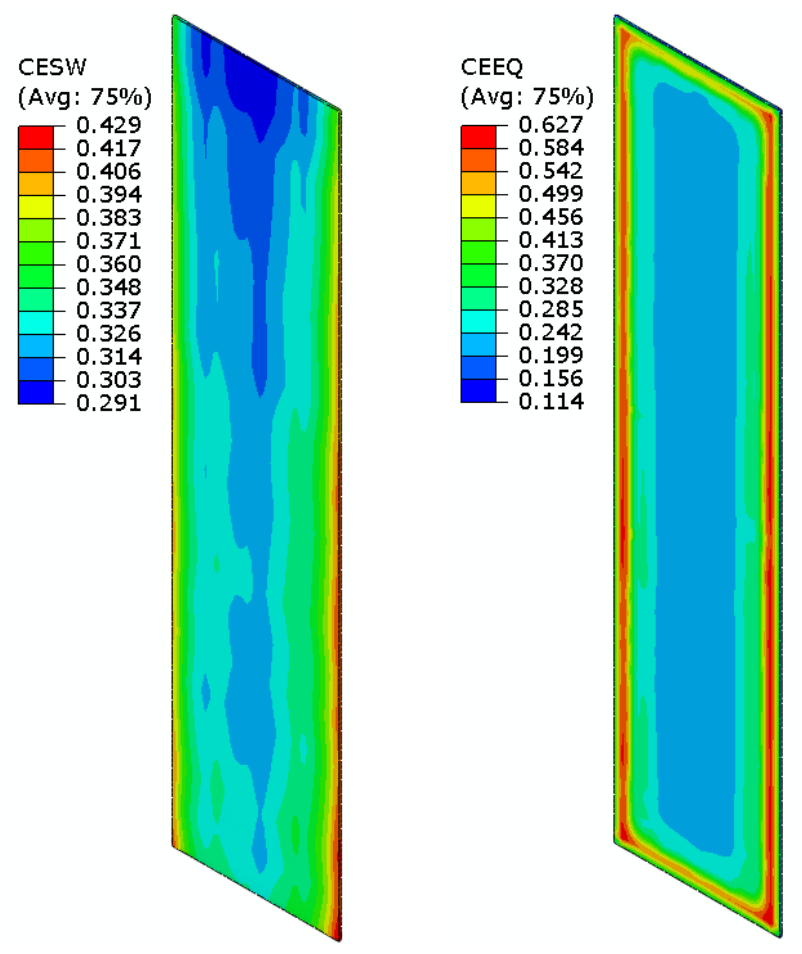

Figure 9 Fuel, end of the irradiation, contours are showing (a) Swelling strain (b) Creep strain

\section{CONCLUSION}

Irradiation performance of a selected plate from MP-1 high power test campaigns (Plate Right-C5) was evaluated. During the course of this work, both fabrication and irradiation stages of the plate were analyzed. The results indicated that fabrication stresses would be comparable with those in mini-plate with $0.254 \mathrm{~mm}$ thick fuel. Irradiation stresses were also similar during irradiation. The stresses at shutdown however, were lower for the plate Right-C5 in MP1 high power case. Fuel centerline temperature at end of life would be approximately $150{ }^{\circ} \mathrm{C}$. Examination of swelling and porosity results indicated that no gas-bubble interconnection would occur. Comparative evaluation of the results with those of selected RERTR12 plates has implied that the temperatures would be below the thresholds. Finally, a mechanically driven failure in high power plates would be unlikely due to absence of high stresses at shutdown. The results have indicated a safe thermo-mechanical irradiation performance for MP1 high power plates.

\section{NOMENCLATURE}

$\begin{array}{lll}\mathrm{A} & \text { Creep rate coefficient } & \mathrm{cm}^{3} / \mathrm{MPa}-\text { fissions } \\ \mathrm{A}_{\mathrm{C}} & \text { Cross sectional area } & \mathrm{m}^{2} \\ \mathrm{C}_{\mathrm{P}} & \text { Specific heat capacity } & \mathrm{J} / \mathrm{kg}-\mathrm{K} \\ \mathrm{D}_{\mathrm{H}} & \text { Hydraulic diameter } & \mathrm{m} . \\ \mathrm{E} & \text { Young's Modulus } & \mathrm{GPa} \\ \mathrm{f} & \text { Friction factor } & - \\ \mathrm{F}_{\mathrm{D}} & \text { Fission density } & \text { fission } / \mathrm{m}^{3} \\ \mathrm{~h} & \text { Heat transfer coefficient } & \mathrm{W} / \mathrm{m}^{2}-\mathrm{K} \\ \mathrm{k} & \text { Thermal Conductivity } & \mathrm{W} / \mathrm{m}-\mathrm{K} \\ \mathrm{Nu} & \text { Nusselt number } & - \\ \mathrm{P} & \text { Porosity } & - \\ \mathrm{P}_{\mathrm{W}} & \text { Wetted perimeter } & \mathrm{m} \\ \mathrm{Pr} & \text { Prandtl number } & - \\ \mathrm{Re} & \text { Reynolds number } & - \\ \mathrm{T} & \text { Temperature } & \mathrm{K} \\ \mathrm{V} & \text { Volume } & \mathrm{m} \\ \lambda & \text { Thermal expansion coefficient } & 1 / \mathrm{K} \\ \alpha & \text { Thermal diffusivity } & \mathrm{m} / \mathrm{sec} \\ \varepsilon & \text { Strain } & - \\ \mu & \text { Dynamic viscosity } & \mathrm{Pa}-\mathrm{sec} \\ \rho & \text { Mass density } & \mathrm{kg} / \mathrm{m}^{3} \\ \sigma & \text { Stress } & \mathrm{MPa} \\ v & \text { Kinematic viscosity } & \mathrm{m} / \mathrm{sec} \\ v & \text { Poisson's ratio } & - \\ & & \end{array}$

\section{ACKNOWLEDGMENTS}

This work was supported by the U.S. Department of Energy, Office of Material Management and Minimization, National Nuclear Security Administration, under DOE-NE Idaho Operations Office Contract DE-AC07-05ID14517. This manuscript was authored by a contractor for the U.S. Government. The publisher, by accepting the article for publication, acknowledges that the U.S. Government retains a nonexclusive, paid-up, irrevocable, worldwide license to publish or reproduce the published form of this manuscript, or allow others to do so, for U.S. Government purposes.

\section{REFERENCES}

[1] J. L. Snelgrove, G. L. Hofman and M. K. Meyer, "Development of very high density low-enriched Uranium fuels," J. Nucl. Eng. Des., vol. 178, p. 119-12, 1997. 
[2] J. F. Jue, H. P. Blair, R. C. Curtis, A. M. Glenn and D. K. Dennis, "Fabrication of monolithic RERTR fuels by Hot Isostatic Pressing," J. Nucl. Tech., vol. 172, no. 2, pp. 204$210,2010$.

[3] J. W. Nielsen, "ECAR-2650: Physics Analysis of the MP-1 High Power Experiment in the ATR South Flux Trap," Idaho National Laboratory, Idaho Falls/ID, 2016.

[4] J. Rest, Y. S. Kim, G. L. Hofman, M. K. Meyer and S. L. Hayes, "U-Mo Fuels Handbook," Nuclear Engineering Division, Argonne National Laboratory, Argonne/IL, 2009.

[5] Y. S. Kim and G. L. Hofman, "Fission product induced swelling of U-Mo alloy fuel," Journal of Nuclear Materials, vol. 419, pp. 291-301, 2011.

[6] G. Beghi, "Gamma Phase Uranium-Molybdenum Fuel Alloys. EURATOM Report No: EUR-4053e," European Atomic Energy Community - EURATOM, Ispra - Italy, 1968.

[7] J. L. Klein, "Uranium and Its Alloys," in Nuclear Reactor Fuel Elements, Ed. A.R. Kaufmann, New York, Wiley, 1962, pp. 31, Chapter 3.

[8] W. R. Lloyd, J. K. Wright, B. H. Rabin, J. L. Schulthess, R. P. Lind, K. M. Wachs, B. J. Frickey and J. Maupin, "INL/LTD-15-34764: Mechanical Properties Characterization of Irradiated U-10Mo Fuel," Idaho National Laboratory, Idaho Falls, ID, 2015.

[9] J. E. Gates, E. G. Bodine, J. C. Bell, A. A. Bauer and G. D. Calkins, "Stres-strain properties of Irradiated Uranium-10 Molybdenum, Report BMI-APDA-638," Battelle Memorial Institute, Columbus/OH, 1958.

[10] Y. S. Kim, G. L. Hofman, J. S. Cheon, A. B. Robinson and D. M. Wachs, "Fission induced swelling and creep of UMo alloy fuel," Journal of Nuclear Materials, vol. 437, pp. 37-46, 2013.

[11] D. J. Alexander, K. D. Clarke and C. Lui, "Tensile Properties of 6061 Aluminum Alloy Materials," Los Alamos National Laboratory. Technical Report LA-UR11-06707., Los Alamos/NM, 2011.

[12] W. R. Llyod, "Evaluation of 6061 Al Alloy Mechanical Properties of HIP-Bonded Fuel Plate Cladding: HIP Bonded Fuel Plates," Technical Report, TEV-1758. Idaho National Laboratory, Idaho Falls/ID., 2014.

[13] S. T. Polkinghorne and J. M. Lacy, "Thermo-physical and mechanical properties of ATR core materials," EG\&G Inc. Technical Report, PG-T-91-031, Idaho Falls/ID, 1991.

[14] J. G. Kaufman, Properties of Aluminum alloys: Tensile, creep and fatigue data at high and low temperatures, Third Edition ed., Materials Park, Ohio, OH: ASM International, 1999, pp. 163-164.

[15] K. Farrell and T. King, "Tensile Properties of NeutronIrradiated 6061 Aluminum Alloy in Annealed and Precipitation-Hardened Conditions," in Effects on Irradiation on Structural Materials, ASTM STP 683,
American Society for Testing and Materials, 1979, pp. 440-449.

[16] K. Farrell, "Assessment of Aluminum Structural Materials for Service Within the ANS Reflector Vessel," Report Number ORNL/TM-13049. Oak Rige National Laboratory, Oak Ridge/TN, 1995.

[17] M. Meyer, B. H. Rabin, J. Cole, I. Glagolenko, W. Jones, J. F. Jue, D. Keiser, C. Miller, G. Moore, H. Ozaltun, F. Rice, A. Robinson, D. Wachs, W. Williams and N. Woolstenhulme, "Research and Development Report for U-Mo Monolithic Fuel," Technical Report, INL/EXT-1740975. Idaho National Laboratory, Idaho Falls/ID., 2016.

[18] W. Mohamed, H. S. Roh and H. Ozaltun, "Evaluation of Uncertainties in Empirical Correlations for Simulation and Modeling of U-10Mo Monolithic Mini-Plate," Technical Evaluation Report, ANL/RTR/TM-16/10. Argonne National Laboratory, Argonne/IL, 2016.

[19] R. T. Webster, ASM Handbook Volume 2: Properties and Selection: Nonferrous Alloys and Special-Purpose Materials, Materials Park, OH: ASM Handbook, ASM International, 1990, p. pp. 661-669.

[20] B. Lustman and F. Kerze, Metallurgy of Zirconium, 1st Edition, New York, Toronto, London: McGraw Hill Inc., 1955.

[21] C. D. Williams and R. W. Gilbert, "Fast neutron damage in $\mathrm{Zr}$ based structural alloys," in Proceedings of the Symposium on Radiation Damage in Solids and Reactor Materials, Vienna, 1969.

[22] E. W. Lemmon, M. L. Huber and M. O. McLinden, "NIST Standard Reference Database 23: Reference Fluid Thermodynamic and Transport Properties - REFPROP, Version 9.0, NIST, Standard Reference Data Program," National Institute of Standards and Technology, Gaithersburg, MD, 2010.

[23] C. B. Jensen, "ECAR-3173: Hydraulic Analysis for the Large B MP-1, CDIPT MP-1, and CDIPT EMPIRE Experiments," Idaho National Laboratory, Idaho Falls, ID, 2016.

[24] C. B. Jensen, "ECAR-3212: Programmatic Thermal Analysis of the MP-1 Experiments," Idaho National Lboratory, Idaho Falls, ID, 2016.

[25] F. P. Incropera and D. P. DeWitt, Introduction to Heat Transfer, Fourth ed., New York, NY: Wiley, ISBN: 0471386499, 2001, pp. 412-417.

[26] R. S. Barnes, "A Theory of swelling and gas release for reactor materials," J. of Nucl. Mater., vol. 11, no. 2, pp. 135-148, 1963.

[27] A. T. Churchman, R. S. Barnes and A. H. Cottrell, "Effects of Heat and Pressure on the Swelling of Irradiated Uranium," J.Nucl. Energy, vol. 7, no. 1-2, pp. 88-96, 1958. 